\title{
Original
}

\section{Differentiation of Dental Pulp-Derived MSCs into Hepatocyte-Like Cells and Their Therapeutic Use for Chemical Liver Injuries of Rats}

\author{
Hajime Hara $^{1)}$, Kimito Sano ${ }^{2)}$, Hiroshi Ishikawa ${ }^{3)}$ and Shogo Ohkoshi ${ }^{1)}$ \\ 1) Department of Internal Medicine, School of Life Dentistry at Niigata, The Nippon Dental University, Niigata, Japan \\ 2) Department of Dental Anesthesiology, School of Life Dentistry at Niigata, The Nippon Dental University, Nitgata, Japan \\ ${ }^{3)}$ Laboratory of Clinical Regenerative Medicine, Faculty of Medicine, University of Tsukuba, Ibaraki, Japan \\ (Accepted for publication, August 29, 2020)
}

\begin{abstract}
Mesenchymal stem cells (MSCs) derived from dental tissues have gained attention in the field of regenerative medicine, in part because they can be obtained from deciduous or extracted teeth. This study aims to investigate the potential of dental pulp-derived MSCs (DP-MSCs) to differentiate into cells with hepatocyte function and to examine the therapeutic effects of these cells on acute chemical liver injuries of rats. MSC fractions from dental pulp were cultured using specific reagents containing activin A and hepatocyte growth factor (HGF). Albumin, fibrinogen, and urea production were assessed and their specific mRNAs were detected by reverse transcription (RT)-PCR. Therapeutic effects of DP-MSCs on rats with acute chemical injuries induced by concanavalin A (ConA) and D-galactosamine (D-gal) were also investigated. DP-MSCs differentiated into polygonal hepatocyte-like cells (HLCs) that produced albumin and converted ammonium to urea. Importantly, HNF4 $\alpha$, which is a liver-specific transcription factor, was expressed in HLCs, confirming the liver-specific properties of HLCs. Administration of HLCs induced significant improvements in liver function following hepatic injury in rats. Thus, DP-MSCs could differentiate into cells with hepatic function. The potential contribution of these cells in regenerative medicine for refractory liver diseases is expected.
\end{abstract}

Key words: Mesenchymal stem cell, Dental pulp, Hepatocyte, Fulminant hepatitis, Regenerative medicine

\section{Introduction}

Mesenchymal stem cells (MSCs) have attracted substantial clinical attention as one of the important cellular resources of regenerative medicine $^{1,2)}$. They reside in many kinds of tissues and differentiate into various cell types. Because MSCs do not require the introduction of foreign genes or proteins for differentiation, unlike induced pluripotent stem (iPS) cells, they may be less tumorigenic. They also cause low ethical concern compared with embryonic stem (ES) cells because they do not involve germ cells. MSCs have immunomodulatory properties, resulting in low risk of immune rejection ${ }^{3)}$. Recently cytotherapy using bone marrow-derived MSCs for acute graft-versus-host disease has been approved $^{4}$.

Gronthos et al. first succeeded in cloning cells derived from dental pulp and showed that such cells rapidly proliferated and could differentiate into a dentin/pulp-like complex under certain culture conditions, indicating the presence of MSCs in dental pulp ${ }^{5}$. Since then, dental pulp-derived MSCs (DP-MSCs) have been reported to differentiate into bone, cartilage, adipose tissue, and neural cells ${ }^{6}$. Because dental pulp is covered by enamel, making it anatomically similar to bone marrow, DPMSCs have similar cell surface markers to bone marrow-derived MSCs (BM-MSCs). It has even be reported that DP-MSCs were more proliferative than $\mathrm{BM}-\mathrm{MSCs}^{7}$.

BM-MSCs were reported to differentiate into cells with hepatocyte

Correspondence to: Dr. Shogo Ohkoshi, Department of Internal Medicine, School of Life Dentistry at Niigata, The Nippon Dental University. 1-8 Hamaura-Cho, Chuo-ku, Niigata-city, 951-8580 Japan; Tel +81-25-211-8243; Fax +81-25-267-1582; E-mail: okoshi@ngt.ndu.ac.jp characteristics $^{8,9)}$. Adipose tissue (AT)- and umbilical cord-derived MSCs were also reported to differentiate into a hepatic lineage $\mathrm{e}^{10,11)}$. Ishkitiev et al. first reported the differentiation of DP-MSCs into cells with a hepatocyte function ${ }^{12}$. They cultured dental pulp cells obtained at the time of extraction of deciduous or wisdom teeth under the presence of insulin-transferrin-selenium- $\mathrm{X}$ and oncostatin $\mathrm{M}$ and found that dental pulp cells differentiated into cells with a polygonal hepatocytic morphology and produced albumin. However, thus far, few reports have shown differentiation of DP-MSC into hepatocytes ${ }^{13-15)}$, and the results must be verified by further studies.

Many studies have attempted to treat severe liver disease with $\mathrm{MSCs}^{16}$. Clinical trials have been reported, including those using BMor AT-MSCs ${ }^{17-19)}$. However, there have been no clinical trials using DPMSCs for decompensated liver cirrhosis or fulminant hepatitis. Because dental-pulp cells are obtained using less invasive methods from extracted deciduous or wisdom teeth, they are considered to be one of the best cellular resources of regenerative medicine, for dental applications as well as for other organs ${ }^{20,21)}$. In fact, some dental-pulp cell banks are currently in operation. Re-utilization of extracted teeth for treatment of severe diseases is an attractive approach for future clinical application ${ }^{15}$.

In this study, we attempted to induce differentiation of dental pulp cells into hepatocytes and examined whether administration of these cells could ameliorate hepatic injury and improve survival in a rat model of fulminant hepatitis. 


\section{Materials and Methods}

\section{Ethical statements}

The study was conducted in accordance with the ethical standards for research involving human and animal subjects described in the Helsinki Declaration (The World Medical Association, 2004).

All protocols for present study were approved by the Research Ethics Committee of Nippon dental University (Approved No. ECNG-R-291).

Animal experimental protocol was approved by the animal experiment ethics committee of School of Life Dentistry at Niigata, The Nippon Dental University (Approved No. H30-200).

\section{Isolation of primary cell cultures and differentiation into hepato- cyte-like cells}

Pulps of wisdom teeth were reached through resorbed root canals and extracted using a sterile barbed broach. The pulp was then digested for $30 \mathrm{~min}$ at $37^{\circ} \mathrm{C}$ in $0.2 \mathrm{mg} / \mathrm{ml}$ collagenase type I (Wako Pure Chemical Industries Ltd. Osaka, Japan), and $1 \mathrm{mg} / \mathrm{ml}$ dispase (Invitrogen, Grand Island, NY, USA). All cell suspensions were seeded into $25-\mathrm{cm}^{2}$ flasks (TPP, Trasadingen, Switzerland) and cultured in growth medium containing DMEM/F12 (Gibco, Grand Island, NY, USA), supplemented with $10 \%$ fetal bovine serum (FBS; Sigma-Aldrich, St. Louis, MO, USA), $100 \mu \mathrm{M}$ glutaMAX (Sigma-Aldrich), $0.1 \%$ minimum essential medium (MEM)-nonessential amino acids (Gibco), $50 \mathrm{U} / \mathrm{ml}$ penicillin (Sigma-Aldrich), $50 \mu \mathrm{g} / \mathrm{ml}$ streptomycin (Sigma-Aldrich), and $0.25 \mu \mathrm{g}$ / $\mathrm{ml}$ Fungizone ${ }^{\circledR}$ (Gibco). MSC fractions were purified using the Friedenstein method ${ }^{22)}$, by which colonies with the greatest proliferating activity were selected and grown. Colonies were differentiated into endodermal cells under the presence of $4 \mathrm{nM}$ human activin A (SBI 800-01, Shenandoah Biotechnology, Warwick, PA, USA), $2 \mathrm{ng} / \mathrm{ml}$ recombinant human basic fibroblast growth factor (FGF, 146 aa) (RSD 233-FB-025, R\&D Systems, Minneapolis, MN, USA), and $1 \mathrm{mM}$ sodium butyrate. Cells were further differentiated into polygonal hepatocyte-like cells (HLCs) using culture medium containing $20 \mathrm{ng} / \mathrm{ml}$ human recombinant HGF (RSD 294-HGN-025/CF, R\&D Systems), $1 \mu \mathrm{g}$ insulin (Merck, 1-034, Darmstadt, Germany), $10^{-7} \mathrm{M}$ dexamethasone (041-18861, Wako Pure Chemical Industries Ltd.), $10 \mathrm{mM}$ nicotinamide (Sigma-Aldrich), and $50 \mu \mathrm{g} \beta$-mercaptoethanol (Sigma-Aldrich).

\section{Transmission electron microscopy}

HLCs were fixed in $2.5 \%$ glutaraldehyde solution for $2 \mathrm{~h}$ at $4^{\circ} \mathrm{C}$, washed in $0.1 \mathrm{M}$ phosphate buffered saline, fixed in $1 \%$ osmium tetroxide for $30 \mathrm{~min}$ at $4{ }^{\circ} \mathrm{C}$, dehydrated in ethanol, penetrated in propylene oxide, embedded in Epon and cut into 90-nm sections. Sections were then stained with $3 \%$ uranyl acetate and lead citrate and observed under a Hitachi-12 A transmission electron microscope (Hitachi, Co., Ltd. Hitachi, Japan)

\section{Hepatocyte function assays}

The presence of the urea cycle may be one of the most characteristic features of matured hepatocytes; thus, we first assayed changes of urea concentrations in HLC culture medium after 24-h exposure of cells to 5 $\mathrm{mmol} / 1 \mathrm{NH}_{4} \mathrm{Cl}$ (Sigma-Aldrich) in order to clarify the time course of urea production. Urea concentrations were measured colorimetrically (QuantiChrom Urea Assay Kit, Bioassay Systems, Hayward, CA, USA). Nephelometry, followed by the bromocresol green assay, was employed to detect human albumin in the culture medium. Fibrinogen and alanine aminotransferase concentration were commercially measured (SRL, Tokyo, Japan). Periodic acid-Schiff (PAS) staining was performed to detect

\begin{tabular}{|c|c|c|}
\hline Primer & Sequence & Product \\
\hline albumin & $\begin{array}{l}\text { sense }: \text { 5'-AATGTTGCCAAGCTGCTGA -3' } \\
\text { antisense : 5'- CTTCCCTTCATCCCGAAGTT -3' }\end{array}$ & $71 \mathrm{bp}$ \\
\hline CPS1 & $\begin{array}{l}\text { sense }: \text { 5'- GAAGGGGCCCGAGAAGTAGAA -3' } \\
\text { antisense : 5'- CTCAACCGGGGCCAGGAAAAC -3' }\end{array}$ & $446 \mathrm{bp}$ \\
\hline ARG1 & $\begin{array}{l}\text { sense }: 5^{\prime} \text { - TTGGCAAGGTGATGGAAGAAACA -3' } \\
\text { antisense : 5'- CCTCCCGAGCAAGTCCGAAACAA -3' }\end{array}$ & 306bp \\
\hline GS & $\begin{array}{l}\text { sense }: 5^{\prime} \text { - GCCTGCTTGTATGCTGGAGTC -3' } \\
\text { antisense : 5'- GGCGCTACGATTGGCTACAC -3' }\end{array}$ & $420 \mathrm{bp}$ \\
\hline Fbg & $\begin{array}{l}\text { sense }: 5 \text { '- GGATCGTCTGCCTGGTCCTA -3' } \\
\text { antisense : 5'- CCTTCAGCTAGAAAGTCACCTTCA -3' }\end{array}$ & $79 \mathrm{bp}$ \\
\hline $\mathrm{HNF} 4 \alpha$ & $\begin{array}{l}\text { sense }: \text { ' }- \text { CCGGGTGTCCATACGCATCCT -3' } \\
\text { antisense : 5'- CAGGTTGTCAATCTTGGCC -3' }\end{array}$ & $322 b p$ \\
\hline GAPDH & $\begin{array}{l}\text { sense }: 5^{\prime} \text { - GTCAAGGCTGAGAACGGGAA -3' } \\
\text { antisense : 5'- GCTTCACCACCTTCTTGATG -3' }\end{array}$ & $513 \mathrm{bp}$ \\
\hline
\end{tabular}

glycogen storage of cells as follows. After $4 \%$ formaldehyde fixation, slides were oxidized in $1 \%$ periodic acid for $5 \mathrm{~min}$ and rinsed in pure water. Slides were then treated with Schiff's reagent (Sigma-Aldrich) for 15 min.

\section{RT-PCR}

Total RNA from $1 \times 10^{6}$ HLCs or DP-MSCs before differentiation into HLCs was extracted using the RNeasy mini kit (QIAGEN, Hilden, Germany) and subjected to reverse transcription (RT)-PCR analysis. Human liver and lung total RNA (BioChain, Newark, CA, USA) were obtained commercially. A total of $0.5 \mu \mathrm{g}$ RNA was subjected to RT-PCR using the SuperScript ${ }^{\mathrm{TM}}$ One-Step RT-PCR System (Invitrogen) using a thermal cycler (StepOne PCR System, Applied Biosystems, Foster City, CA, USA). The cycle parameters were $94^{\circ} \mathrm{C}$ for $2 \mathrm{~min}$, followed by 40 cycles of $95^{\circ} \mathrm{C}$ for $15 \mathrm{sec}, 55^{\circ} \mathrm{C}$ for $30 \mathrm{sec}$, and $72^{\circ} \mathrm{C}$ for $1 \mathrm{~min}$. Primers used are listed in Table 1.

\section{Animal experiment protocols}

Four-week-old male Sprague-Dawley rats (body weight, $100 \mathrm{~g}$; CLEA Japan Inc., Tokyo) were used. Animals received a single injection of concanavalin A (ConA, Sigma-Aldrich) diluted with phosphate-buffered saline via the tail vein at $20 \mathrm{mg} / \mathrm{kg}$ and D-galactosamine (D-gal, Sigma-Aldrich) dissolved in physiological saline and adjusted to $\mathrm{pH} 7.3$ with $1 \mathrm{~N} \mathrm{NaOH}$ intraperitoneally at $1.2 \mathrm{~g} / \mathrm{kg}$. Immediately after administration, HLCs were administered into tail veins. Jaundice and sickness levels of animals were carefully observed. Blood samples were obtained from the tail veins of animals at 24,48 , and $72 \mathrm{~h}$, at which time they were sacrificed.

\section{Immunohistochemistry}

Rat liver and lung tissues were fixed in $4 \%$ buffered formaldehyde, dehydrated and embedded in paraffin. Sections were stained with hematoxylin-eosin (HE). For immunohistochemistry, sections were treated with Immunosaver (Nissin EM, Tokyo, Japan). After endogenous peroxidase activity was blocked with $0.3 \%$ hydrogen chloride ethanol, slides were incubated with anti-human albumin (ab137885, Abcam, Cambridge, UK) or anti-human mitochondria antibody (clone 113-1, EMD Millipore, CA, USA) at $4^{\circ} \mathrm{C}$ overnight. Slides were then incubated with peroxidase-labeled anti-rabbit or mouse IgG (Nichirei Bioscience, To- 

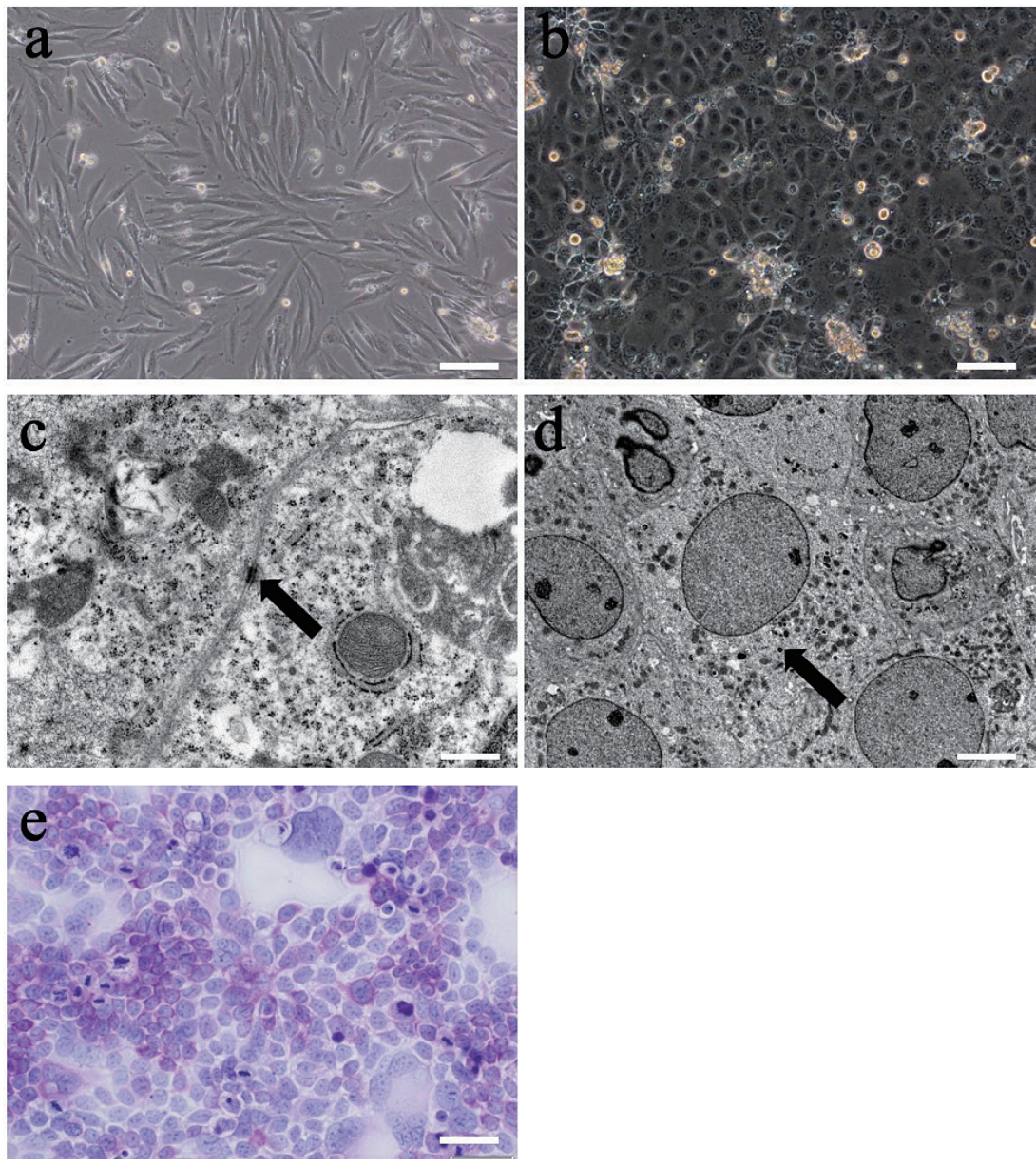

Figure 1. a, b) Phase-contrast microscopic images of cell morphology. Fibroblast-like cells turned into polygonal hepatocyte-like cells under specific culture conditions. c, d) Transmission electron microscopic pictures of cells with desmosome-like and glycogen-like structures (arrows). e) PAS staining of HLCs. Scale bars are $100 \mu \mathrm{m}$ for a, b, $2.0 \mu \mathrm{m}$ for c, d, and $50 \mu \mathrm{m}$ for e.

kyo, Japan), respectively. The color was developed using diaminobenzidine (Nichirei Bioscience).

\section{Statistical analyses}

Significant differences between control and experimental animals were evaluated using Kaplan-Meier survival analysis with the log-rank test. Two-way repeated measures ANOVA was used to compare changes in laboratory test values between control and experimental animals. All statistical procedures were carried out using IBM SPSS Statistics 23 (Chicago, IL, USA). P values $<0.05$ were considered to be statistically significant.

\section{Results}

\section{Histological characterization of HLCs}

Differentiation of DP-MSCs into polygonal HLCs occurred within 4 weeks. Phase-contrast microscopic images of DP-MSCs and HLCs showed cells with spindle-shaped fibroblast-like and polygonal hepatocyte-like morphology, respectively (Fig. 1a, b). Transmission electron microscopy showed the presence of desmosome-like structures at the cell membrane contacting adjacent cells and glycogen-like granules in the cytoplasm (arrows) (Fig. 1c, d). PAS staining showed the accumulation of glycogen in cells (Fig. 1e).

\section{Hepatocyte function assays of HLCS}

We examined changes of urea concentrations in the culture medium of HLCs containing $5 \mathrm{mM}$ ammonium chloride (Fig. 2Aa). Urea concentrations increased during the time course and peaked at $40 \mathrm{~min}$, suggesting the presence of the urea cycle as a characteristic feature of mature hepatocytes. Along with urea production in the culture medium, human albumin, alanine aminotransferase, fibrinogen, and hepaplastin activities were also detected (Fig. 2A b, c, d, e), confirming the hepatogenic characteristics of DP-MSC-derived HLCs.

\section{Confirmation of $m R N A$ expression of HLCs}

In concordance with these hepatocyte-specific biological activities, i.e. mRNA expression of albumin, fibrinogen, and genes responsible for urea production such as glutamine synthetase (GS), arginase 1 (ARG1), and carbamoyl phosphatase synthetase 1 (CPS1) were confirmed by RTPCR (Fig. 2B b, c, d, e). We especially compared the expression level of albumin mRNA from original DP-MSCs with that from HLCs (Fig 2Bb, lane 3 and 4). Albumin mRNA was detected more strongly in HLCs than in DP-MSCs. In addition, the expression of hepatocyte nuclear factor- $4 \alpha(\mathrm{HNF} 4 \alpha)$ mRNA, which regulates many hepatocyte-specific genes, was confirmed in HLCs (Fig. 2Bc). 


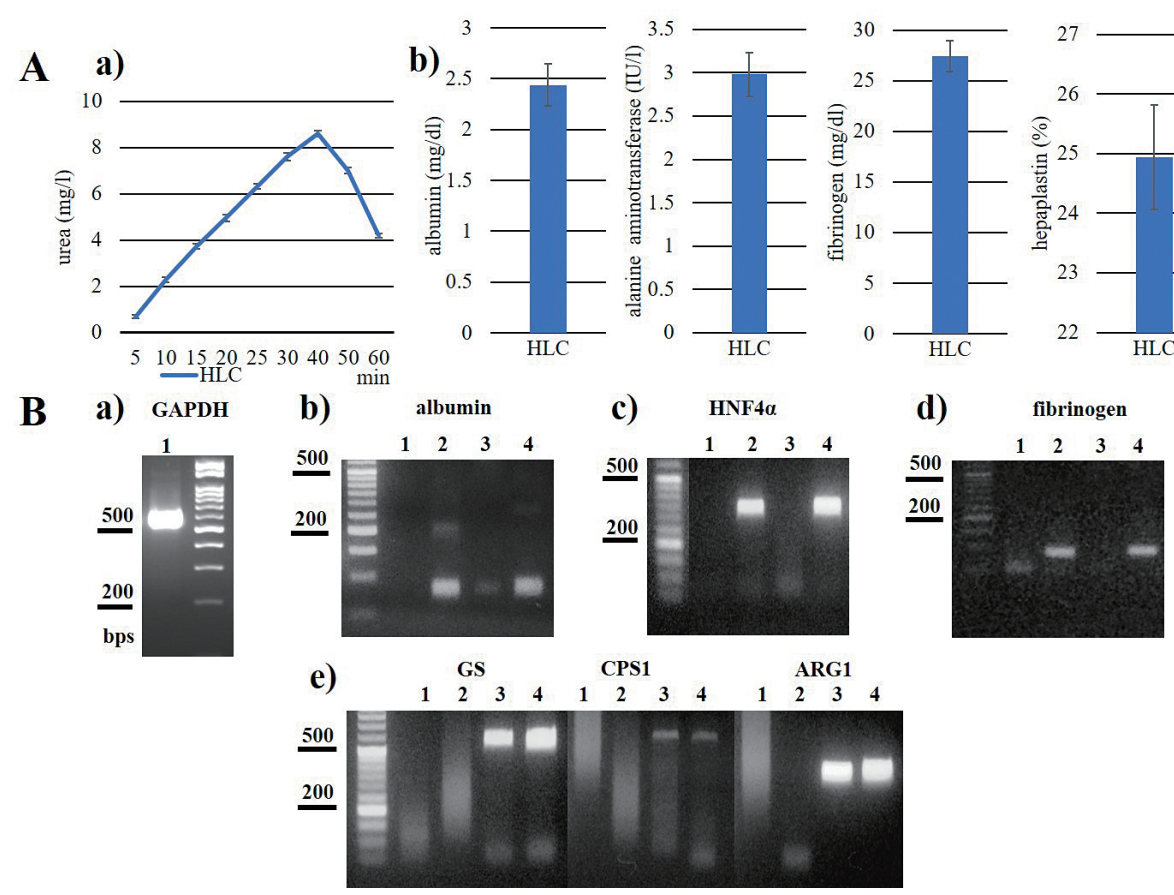

Figure 2. A. a) A time-course of changes of urea concentrations in the culture medium of HLCs. b) Concentrations of albumin, alanine aminotransferase (ALT), fibrinogen, and hepaplastin obtained from 3rd day cultures. B. Results of RT-PCR analyses of (a) GAPDH, (b) albumin, (c) HNF4 $\alpha$, and (d) fibrinogen, and (e) GS, CPS1, and ARG1. a) Lane 1: HLC, b) Lane 1: buffer control, 2: human liver, 3: DP-MSC, 4: HLC. c) Lane 1: buffer control, 2: human liver, 3: human lung, 4: HLC. d) Lane 1: buffer control, 2: human liver, 3: human lung, 4: HLC. e) Lane 1: buffer control, 2: human lung, 3: human liver, 4: HLC.

A Protocols of animal experiments

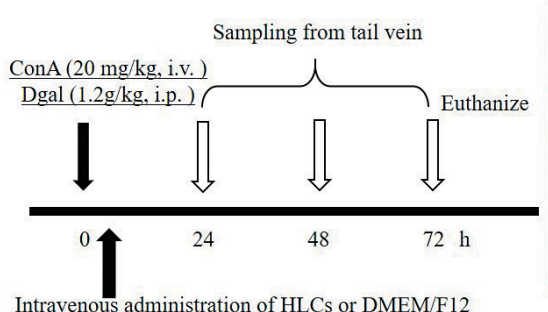

C

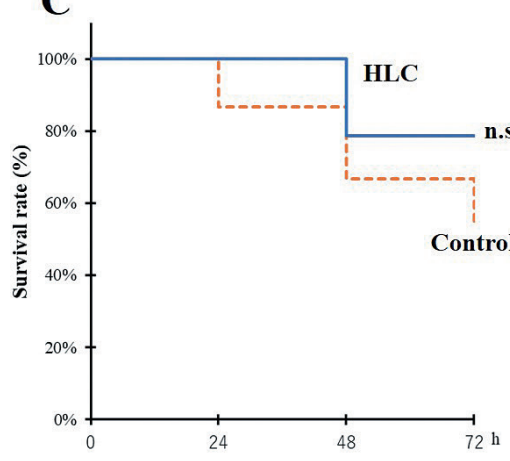

B
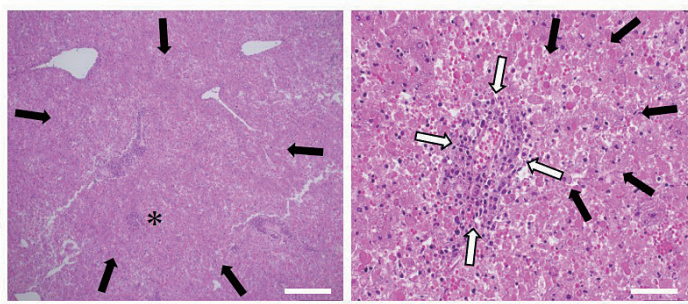

D
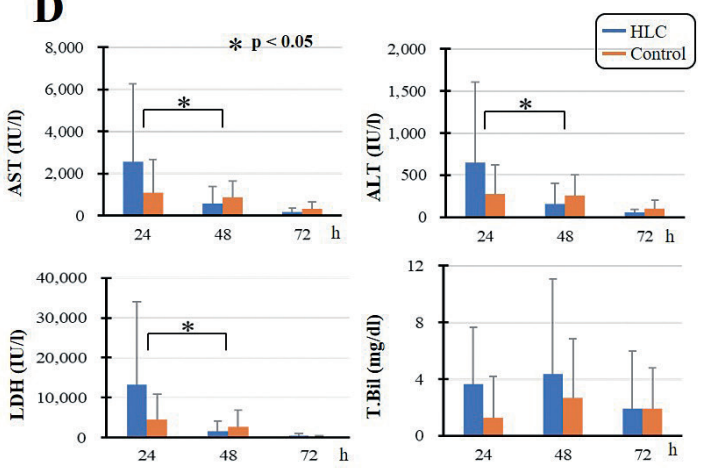

Figure 3. A. Experimental protocol of HLC transplantation. Immediately following injection of Con A and D-Gal, HLCs or control medium (DMEM/F12) were administered via the tail. Blood samples were taken at 24, 48, $72 \mathrm{~h}$ after administration. B. Histological images of liver samples obtained at $72 \mathrm{~h}$ showed massive necrosis with lymphocytes infiltration (left: lower magnification, scale bar $=400 \mu$ m; right: higher magnification, scale bar $=100 \mu \mathrm{m} . *$ indicates the area magnified. Areas of massive hepatic necrosis were observed throughout the slides (left). The severe area are roughly indicated by black arrows, and white arrows indicate lymphocytes infiltrations. C. Kaplan-Meier survival analysis of control and HLC-treated animals. D. Changes in mean AST, ALT, LDH, and T.Bil values. Blue and orange lines/bars indicate HLC and control groups, respectively. Data of standard deviation were omitted. Decreases in AST, ALT and LDH from 24 to $48 \mathrm{~h}$ were significantly higher in HLC-administered animals. 
A
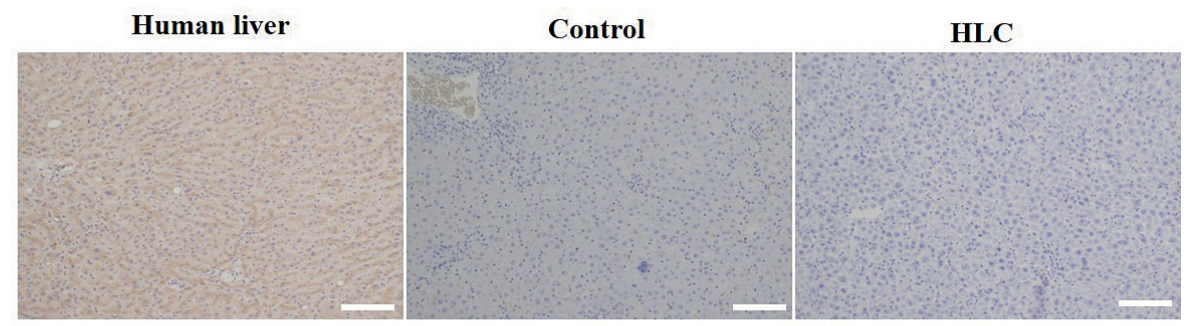

B

Human liver

Control

HLC
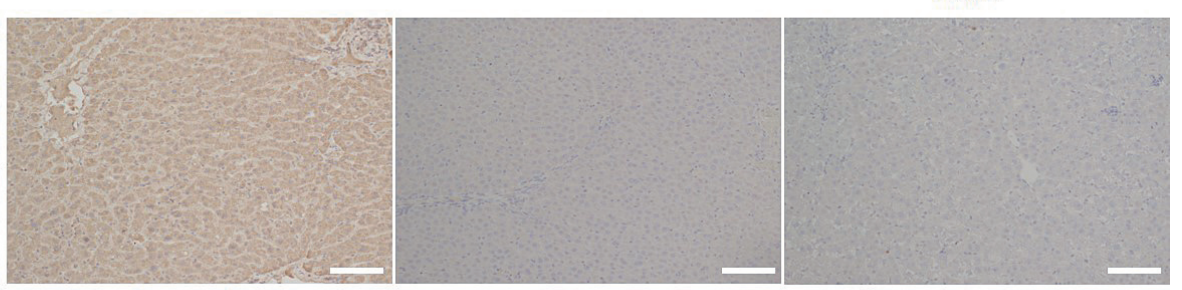

C

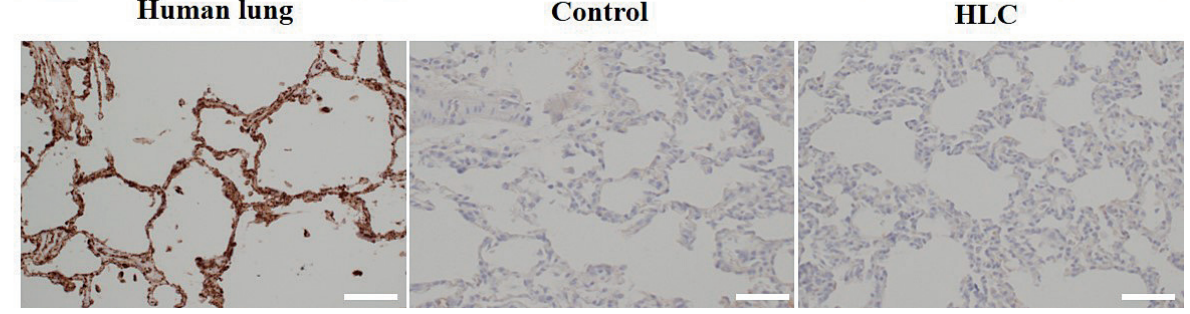

Figure 4. Representative immunohistochemical staining images for human albumin (A) and mitochondria (B) in liver sections from the control and HLC (right) groups, showing the absence of hepatocytes that are clearly positive for human albumin and mitochondria. Lung sections from the control and HLC (right) showing no cells positive for human mitochondria are shown in (C). Positive controls from human liver (A,B) and lung (C) are shown at left. Scale bars $=100 \mu \mathrm{m}$.

\section{Transplantation of HLCs to an animal model of Con A and D-gal in- duced hepatitis}

Immediately after administration of ConA and D-gal, $1.5 \times 10^{6}$ HLCs $(\mathrm{n}=14$, experimental group) and DMEM/F12 (Gibco) $(\mathrm{n}=15$, control group) were administered into tail veins (Fig. 3A). Blood samples were obtained from tail veins at 24,48 , and $72 \mathrm{~h}$ after transplantation at which point the animals were sacrificed. We first co-administered ConA and D-gal to one rat and it displayed severe hepatic injury (AST: $7,190 \mathrm{IU} / 1$ and jaundice with total bilirubin level of $6.73 \mathrm{mg} / \mathrm{dl}$ ), which was deemed sufficient to evaluate the therapeutic effects of DP-MSCderived hepatocytes on hepatic injury. Histological findings showed massive hepatic necrosis throughout the slides (severe parts are indicated by black arrows.) with lymphocyte infiltration (white arrows) (Fig. 3B).

Seven of 15 control and 3 of 14 HCLs-treated animals died during the $72 \mathrm{~h}$ observation period. Kaplan-Meier survival analysis showed no significant difference between control and experimental groups during this time period (Fig. 3C). Changes in AST, ALT, LDH, and total bilirubin (T.Bil, mg/dl) levels were observed (Fig. 3D). A significant reduction in AST, ALT and LDH were observed from 24 to $48 \mathrm{~h}$ in HCLs-treated animals compared with controls (P values $<0.05$ ).

We then attempted to examine whether HLCs were detected in rat livers following administration of HLCs, by using antibodies specific for human albumin and mitochondria (Fig. 4A, B). No clearly-positive human cells were found using either antibody. In addition, there were no positive human cells in rat lungs following HLCs administration (Fig. 4C). Human liver sections as positive controls for albumin and mitochondria, lung section for mitochondria are also shown.

\section{Discussion}

Liver diseases have a variety of etiologies, including hepatitis viruses, metabolic or genetic disorders, alcohol and drugs. Although recent progress in treatment has contributed to improvement in the prognosis of liver disease, liver transplantation is currently the only cure for patients with irreversible decompensated liver cirrhosis or fatal fulminant hepatitis. Regenerative medicine represents new hope in the treatment of these intractable diseases. There have been many experimental and clinical trials for these diseases using tissue-derived $\mathrm{MSCs}^{16,23-25)}$.

There are two main mechanisms for MSCs to exert their pharmacological effects. Many studies have attempted to clarify the ability of MSCs to differentiate and replace damaged resident cells. In most cases, however, engrafted MSCs tend to be short-lived ${ }^{26)}$, suggesting other mechanisms for them to exert therapeutic effects. Currently, the primary mechanism of MSCs appears to be mediated through its immunoregulatory properties ${ }^{3)}$.

The liver is a central organ of metabolism. Albumin and clotting factors such as fibrinogen are synthesized in the liver. The typical function of the liver includes glycogen synthesis and urea production through the urea cycle. In this study, urea concentrations increased in the culture medium. Along with the detection of albumin, aminotransferase, fibrinogen, and hepaplastin activities, we confirmed the presence of mRNAs for enzymes involved in the urea cycle, as well as albumin and fibrinogen mRNAs, indicating that DP-MSCs acquired hepatic properties under culture conditions conductive to inducing hepatic differentiation. Notably, albumin mRNA was induced under the conditions where DPMSCs differentiated into HLCs, showing that hepatocyte properties were obtained during the differentiation process from DP-MSCs. DP- 
MSCs have a gene expression profile that is similar to that of BM$\mathrm{MSCs}^{27}$. Kumar et al. showed a higher expression of hepatic markers in DP-MSCs than BM-MSCs ${ }^{28)}$. In this study, HNF $4 \alpha$ mRNA, which is essential for hepatic function and regulates many hepatocyte-specific genes, was detected, confirming the hepatocyte character of these cells $^{29)}$. Because HLCs derived from umbilical cord-MSCs did not express $\mathrm{HNF} 4^{10}$, our finding might indicate the hepatocyte-prone nature of DP-MSCs ${ }^{28,30)}$, In addition, HNF4 $\alpha$ was also reported to promote definitive endoderm differentiation from human iPS cells ${ }^{31}$.

Regarding the culture conditions, Lee et al. utilized a two-step induction method to differentiate BM-MSCs into HLCs by first using hepatocyte growth factor (HGF) and basic fibroblast growth factor (bFGF), followed by oncostatin $\mathrm{M}^{32)}$. Banas et al. applied similar methods to differentiate adipose tissue-MSCs into $\mathrm{HLCs}^{11}$. These factors are commonly reported to be essential for differentiating MSCs into HLCs. We specifically used activin A and FGF in the first step and HGF in the second step. Activin A is a differentiation-inducing factor that belongs to the TGF $\beta$ family. As a result, the phenotypes of hepatocytes became very stable, and were not lost even after storage in liquid nitrogen. However, the induced-cells showed characteristics of hepatocytes only in the presence of growths factors, and the phenotypes were lost after the withdrawal of growth factors when other culture methods were taken (personal experience). Han et al. also used Activin A to differentiate DPMSCs into definitive endoderm, which is an interface during endodermal differentiation, bridging the final stage of hepatic differentiation $^{33)}$.

Shi et al. reported that human BM-MSCs infused via intrahepatic portal veins constituted only approximately $4.5 \%$ of pig hepatocytes with D-gal-induced fulminant hepatitis ${ }^{34)}$. They also showed that trans-differentiation of implanted BM-MSCs was close to completion at day 7 , concluding that paracrine effects played an important role in MSC-assisted liver restoration. In our study, although not significant, the survival rate of rats infused with HLCs was higher than that of control animals. ConA induces T-cell-mediated liver damage, and D-gal enhances TNF- $\alpha$ levels of Kupffer cells, inhibiting mRNAs of anti-apoptotic genes ${ }^{35)}$. Therefore, liver injury caused by these reagents are induced by immune reaction and are a good model to evaluate the immunomodulatory effects of MSCs-derived cells. In this study, the reduction of AST, ALT and LDH levels from 24 to $48 \mathrm{~h}$ was significantly higher in treated rats compared with control rats. In addition, we could not detect cells that were positive specifically for human albumin and mitochondria in livers of rats infused with HLCs. We speculated that the therapeutic effects of our treatment might be due to paracrine and immunomodulatory effects of DP-MSCs-derived HLCs, considering that a large number of cells infused intravenously might be trapped in the lungs ${ }^{3)}$. However, we were unable to detect human cells in rat lungs; thus, this paracrine mechanisms could not be confirmed. The reason for this may be because the rats were harvested $72 \mathrm{~h}$ after cell administration, which might be too late to observe surviving HLCs in the liver and lung tissues. Although there have been no reports demonstrating paracrine function in MSC-derived hepatocytes to ameliorate disease, several reports showed that a paracrine-mechanism was involved in pathogenic improvements by growth-factor-treated MSCs, possibly supporting our hypothesis ${ }^{36-38)}$. In addition, a recent report showed the importance of macrophage polarization in the therapeutic effects of DP-MSCs ${ }^{39}$.

Dental pulp cells obtained by less invasive methods can be stored at dental pulp-cell banks ${ }^{40)}$. One possible implication of our study may be the utilization of DP-MSCs as an important cellular resource to treat refractory liver diseases.
In conclusions, DP-MSCs are a promising resource for regenerative medicine because of their differentiation potential, biosafety, and relatively non-invasive collection method. We found that DP-MSCs could differentiate into cells with hepatic function. We also found that administration of HLCs led to a possible improvement of liver functions in a rat model of fulminant hepatitis. The contribution of these cells in regenerative medicine for refractory liver diseases can be expected.

\section{Acknowledgements}

We would like to extend our gratitude to Dr. Yukio Miyagawa, the specially appointed professor of The Nippon Dental University, who provided guidance for this study.

This work was supported by Grants-in-Aid for Scientific Research on Priority Areas from the Ministry of Education, Science and Technology of Japan (19K24106 to H.H. and 17K08966 to S.O).

\section{Conflict of Interest}

The authors do not have any commercial affiliation or consultancy that could be construed as a conflict of interest.

\section{References}

1. Bianco P. "Mesenchymal" stem cells. Annu Rev Cell Dev Biol 30: 677-704, 2014

2. Sharpe PT. Dental mesenchymal stem cells. Development 143: 2273-2280, 2016

3. Wang Y, Chen X, Cao W and Shi Y. Plasticity of mesenchymal stem cells in immunomodulation: pathological and therapeutic implications. Nat Immunol 15: 1009-1016, 2014

4. Muroi K, Miyamura K, Okada M, Yamashita T, Murata M, Ishikawa T, Uike N, Hidaka M, Kobayashi R, Imamura M, Tanaka J, Ohashi K, Taniguchi S, Ikeda T, Eto T, Mori M, Yamaoka M and Ozawa K. Bone marrow-derived mesenchymal stem cells (JR-031) for steroid-refractory grade III or IV acute graft-versus-host disease: a phase II/III study. Int J Hematol 103: 243-250, 2016

5. Gronthos S, Mankani M, Brahim J, Robey PG and Shi S. Postnatal human dental pulp stem cells (DPSCs) in vitro and in vivo. Proc Natl Acad Sci U S A 97: 13625-13630, 2000

6. Gronthos S, Brahim J, Li W, Fisher LW, Cherman N, Boyde A, DenBesten P, Robey PG and Shi S. Stem cell properties of human dental pulp stem cells. J Dent Res 81: 531-535, 2002

7. Kunimatsu R, Nakajima T, Awada T, Tsuka Y, Abe T, Ando K, Hiraki T, Kimura A and Tanimoto K. Comparative characterization of stem cells from human exfoliated deciduous teeth, dental pulp, and bone marrow-derived mesenchymal stem cells. Biochem Biophys Res Commun 501: 193-198, 2018

8. Lagasse E, Connors H, Al-Dhalimy M, Reitsma M, Dohse M, Osborne L, Wang X, Finegold M, Weissman IL and Grompe M. Purified hematopoietic stem cells can differentiate into hepatocytes in vivo. Nat Med 6: 1229-1234, 2000

9. Schwartz RE, Reyes M, Koodie L, Jiang Y, Blackstad M, Lund T, Lenvik T, Johnson S, Hu WS and Verfaillie CM. Multipotent adult progenitor cells from bone marrow differentiate into functional hepatocyte-like cells. J Clin Invest 109: 1291-1302, 2002

10. Campard D, Lysy PA, Najimi M and Sokal EM. Native umbilical cord matrix stem cells express hepatic markers and differentiate into hepatocyte-like cells. Gastroenterology 134: 833-848, 2008

11. Banas A, Teratani T, Yamamoto Y, Tokuhara M, Takeshita F, Quinn G, Okochi H and Ochiya T. Adipose tissue-derived mesenchymal stem cells as a source of human hepatocytes. Hepatology 46: 219- 
Hajime Hara et al:: Therapeutic Use of Dental Pulp Cells

228,2007

12. Ishkitiev N, Yaegaki K, Calenic B, Nakahara T, Ishikawa H, Mitiev $\mathrm{V}$ and Haapasalo M. Deciduous and permanent dental pulp mesenchymal cells acquire hepatic morphologic and functional features in vitro. J Endod 36: 469-474, 2010

13. Ishkitiev N, Yaegaki K, Imai T, Tanaka T, Fushimi N, Mitev V, Okada M, Tominaga N, Ono S and Ishikawa H. Novel management of acute or secondary biliary liver conditions using hepatically differentiated human dental pulp cells. Tissue Eng Part A 21: 586-593, 2015

14. Patil R, Kumar BM, Lee WJ, Jeon RH, Jang SJ, Lee YM, Park BW, Byun JH, Ahn CS, Kim JW and Rho GJ. Multilineage potential and proteomic profiling of human dental stem cells derived from a single donor. Exp Cell Res 320: 92-107, 2014

15. Ohkoshi S, Hirono H, Nakahara T and Ishikawa H. Dental pulp cell bank as a possible future source of individual hepatocytes. World J Hepatol 10: 702-707, 2018

16. Lee CW, Chen YF, Wu HH and Lee OK. Historical perspectives and advances in mesenchymal stem cell research for the treatment of liver diseases. Gastroenterology 154: 46-56, 2018

17. Terai S, Ishikawa T, Omori K, Aoyama K, Marumoto Y, Urata Y, Yokoyama Y, Uchida K, Yamasaki, T Fujii Y, Okita K and Sakaida I. Improved liver function in patients with liver cirrhosis after autologous bone marrow cell infusion therapy. Stem Cells 24: 2292-2298, 2006

18. Pai M, Zacharoulis D, Milicevic MN, Helmy S, Jiao LR, Levicar N, Tait P, Scott M, Marley SB, Jestice K, Glibetic M, Bansi D, Khan SA, Kyriakou D, Rountas C, Thillainayagam A, Nicholls JP, Jensen S, Apperley JF, Gordon MY and Habib NA. Autologous infusion of expanded mobilized adult bone marrow-derived CD34+ cells into patients with alcoholic liver cirrhosis. Am J Gastroenterol 103: 1952-1958, 2008

19. Sakai Y, Takamura M, Seki A, Sunagozaka H, Terashima T, Komura T, Yamato M, Miyazawa M, Kawaguchi K, Nasti A, Mochida H, Usui S, Otani N, Ochiya T, Wada T, Honda M and Kaneko S. Phase I clinical study of liver regenerative therapy for cirrhosis by intrahepatic arterial infusion of freshly isolated autologous adipose tissue-derived stromal/stem (regenerative) cell. Regen Ther 6: 52-64, 2017

20. Arora V, Arora P and Munshi AK. Banking stem cells from human exfoliated deciduous teeth (SHED): saving for the future. J Clin Pediatr Dent 33: 289-294, 2009

21. Collart-Dutilleul PY, Chaubron F, De Vos J and Cuisinier FJ. Allogenic banking of dental pulp stem cells for innovative therapeutics. World J Stem Cells 7: 1010-1021, 2015

22. Friedenstein AJ, Chailakhjan RK and Lalykina KS. The development of fibroblast colonies in monolayer cultures of guinea-pig bone marrow and spleen cells. Cell Tissue Kinet 3: 393-403, 1970

23. Shiota $G$ and Itaba N. Progress in stem cell-based therapy for liver disease. Hepatol Res 47: 127-141, 2017

24. Terai S and Tsuchiya A. Status of and candidates for cell therapy in liver cirrhosis: overcoming the "point of no return" in advanced liver cirrhosis. J Gastroenterol 52: 129-140, 2017

25. Tsuchiya A, Kojima Y, Ikarashi S, Seino S, Watanabe Y, Kawata Y and Terai S. Clinical trials using mesenchymal stem cells in liver diseases and inflammatory bowel diseases. Inflamm Regen 37: 16, 2017

26. von Bahr L, Batsis I, Moll G, Hagg M, Szakos A, Sundberg B, Uzunel M, Ringden $\mathrm{O}$ and Le Blanc $\mathrm{K}$. Analysis of tissues following mesenchymal stromal cell therapy in humans indicates limited long- term engraftment and no ectopic tissue formation. Stem Cells 30: 1575-1578, 2012

27. Okada M, Ishkitiev N, Yaegaki K, Imai T, Tanaka T, Fukuda M, Ono S and Haapasalo M. Hydrogen sulphide increases hepatic differentiation of human tooth pulp stem cells compared with human bone marrow stem cells. Int Endod J 47: 1142-1150, 2014

28. Kumar A, Kumar V, Rattan V, Jha V, Pal A and Bhattacharyya S. Molecular spectrum of secretome regulates the relative hepatogenic potential of mesenchymal stem cells from bone marrow and dental tissue. Sci Rep 7: 15015, 2017

29. Watt AJ, Garrison WD and Duncan SA. HNF4: a central regulator of hepatocyte differentiation and function. Hepatology 37: 12491253,2003

30. Ishkitiev N, Yaegaki K, Imai T, Tanaka T, Nakahara T, Ishikawa H, Mitev V and Haapasalo M. High-purity hepatic lineage differentiated from dental pulp stem cells in serum-free medium. J Endod 38: 475-480, 2012

31. Hanawa M, Takayama K, Sakurai F, Tachibana M and Mizuguchi H. Hepatocyte nuclear factor 4 alpha promotes definitive endoderm differentiation from human induced pluripotent stem cells. Stem Cell Rev 13: 542-551, 2017

32. Lee KD, Kuo TK, Whang-Peng J, Chung YF, Lin CT, Chou SH, Chen JR, Chen YP and Lee OK. In vitro hepatic differentiation of human mesenchymal stem cells. Hepatology 40: 1275-1284, 2004

33. Han YJ, Kang YH, Shivakumar SB, Bharti D, Son YB, Choi YH, Park WU, Byun JH, Rho GJ and Park BW. Stem cells from cryopreserved human dental pulp tissues sequentially differentiate into definitive endoderm and hepatocyte-Like cells in vitro. Int J Med Sci 14: 1418-1429, 2017

34. Shi D, Zhang J, Zhou Q, Xin J, Jiang J, Jiang L, Wu T, Li J, Ding W, Li J, Sun S, Li J, Zhou N, Zhang L, Jin L, Hao S, Chen P, Cao H, Li M, Li L, Chen X and Li J. Quantitative evaluation of human bone mesenchymal stem cells rescuing fulminant hepatic failure in pigs. Gut 66: 955-964, 2017

35. Maes M, Vinken M and Jaeschke H. Experimental models of hepatotoxicity related to acute liver failure. Toxicol Appl Pharmacol 290: 86-97, 2016

36. Kong F, Shi X, Xiao F, Yang Y, Zhang X, Wang LS, Wu CT and Wang H. Transplantation of hepatocyte growth factor-modified dental pulp stem cells prevents bone loss in the early phase of ovariectomy-induced osteoporosis. Hum Gene Ther 29: 271-282, 2018

37. Tang WP, Akahoshi T, Piao JS, Narahara S, Murata M, Kawano T, Hamano N, Ikeda T and Hashizume M. Basic fibroblast growth factor-treated adipose tissue-derived mesenchymal stem cell infusion to ameliorate liver cirrhosis via paracrine hepatocyte growth factor. J Gastroenterol Hepatol 30: 1065-1074, 2015

38. Lan YW, Theng SM, Huang TT, Choo KB, Chen CM, Kuo HP and Chong KY. Oncostatin M-preconditioned mesenchymal stem cells alleviate bleomycin-induced pulmonary fibrosis through paracrine effects of the hepatocyte growth factor. Stem Cells Transl Med 6: 1006-1017, 2017

39. Ito T, Ishigami M, Matsushita $Y$, Hirata M, Matsubara K, Ishikawa T, Hibi H, Ueda M, Hirooka Y, Goto H and Yamamoto A. Secreted ectodomain of SIGLEC-9 and MCP-1 synergistically improve acute liver failure in rats by altering macrophage polarity. Sci Rep 7: 44043, 2017

40. Tamaki Y, Nakahara T, Ishikawa $\mathrm{H}$ and Sato $\mathrm{S}$. In vitro analysis of mesenchymal stem cells derived from human teeth and bone marrow. Odontology 101(2): 121-132, 2013 
J.Hard Tissue Biology Vol. 29(4): 215-222, 2020 